\title{
Plasma concentration of presepsin and its relationship to the diagnosis of infections in multiple trauma patients admitted to intensive care
}

\author{
Monica Sparacino, ${ }^{1}$ Emanuele Russo, ${ }^{2}$ Sofia Vitali, ${ }^{2}$ Arianna Torri, ${ }^{1}$ Maria Federica Pedna, ${ }^{1}$ \\ Mariangela Di Viesti, ${ }^{1}$ Marina Gagliardi, ${ }^{1}$ Elisabetta Crepaldi, ${ }^{1}$ Monica Castiglioni, ${ }^{1}$ Vanni Agnoletti, ${ }^{2}$ \\ Vittorio Sambri ${ }^{1,3}$ \\ ${ }^{1}$ Unit of Microbiology, the Hub Laboratory of the Great Romagna, Pievesestina; ${ }^{2}$ Intensive Care Unit, M. Bufalini \\ Hospital, Cesena; ${ }^{3}$ DIMES, University of Bologna, Italy
}

\section{Summary}

Background and aims: Septic complications represent the predominant cause of late death in poly-trauma patients. The necessity to differentiate septic from non septic patients is more relevant at the early stage of the illness in order to improve the clinical outcome and to reduce the mortality. The identification of a sensitive and specific, clinically reliable, biomarker capable to early recognize incoming septic complications in trauma patients whose expression is not influenced by concomitant traumatic injuries, is still a challenge for the researchers in the field.

Materials and methods: A retrospective analysis on 48 adult

Correspondence: Monica Sparacino, Unit of Microbiology, The Hub Laboratory of the Great Romagna, Piazza della Liberazione 60, 47522 Pievesestina (FC), Italy.

Tel.: +39.0547.394811.

E-mail: monica.sparacino@auslromagna.it

Key words: Presepsin; Trauma; Sepsis; SIRS.

Contributions: MS, ER and VS designed the study; SV and ER performed the clinical evaluation of the patients, AT and MFP supervised the laboratory testing, MDV, MG, EC and MC performed the tests, MS, ER wrote the manuscript; VA and VS reviewed the manuscript.

Conflict of interest: the authors declare no potential conflict of interest. The presepsin tests were provided free of charge by GEPA Srl (Bollate, Italy) and this company had no influence on the design of the study.

Acknowledgements: This work is dedicated to the memory of Giorgio Gambale, MD, who passed away just a few months after the beginning of the study. Giorgio has been one of the principal promoter of the investigation and we all want to thank him.

Received for publication: 30 June 2017.

Accepted for publication: 30 June 2017.

(C) Copyright M. Sparacino et al., 2017

Licensee PAGEPress, Italy

Microbiologia Medica 2017; 32:6870

doi:10.4081/mm.2017.6870

This article is distributed under the terms of the Creative Commons Attribution Noncommercial License (by-nc 4.0) which permits any noncommercial use, distribution, and reproduction in any medium, provided the original author(s) and source are credited. patients ( 9 females and 39 males, mean age $47.6 \pm 19$ years) with multiple trauma was performed. The inclusion criterion was to suffer from acute trauma since no more than 24 hours and the exclusion criteria were the following: antibiotic treatment on admission and maintained for more than 48 hours; on-going infection on admission not associated with trauma; treatment with immunosuppressors/ immunomodulants; age $<18$ years old. Presepsin was measured using an automated chemiluminescence analyser at 1, 3, 5 and 8 days post of hospitalization. The diagnosis of systemic inflammatory response syndrome (SIRS)/infection was established according to the criteria of the Surviving Sepsis Campaign.

Results and conclusions: In patients with SIRS, the mean presepsin concentration was 917,08 $( \pm 69.042) \mathrm{ng} / \mathrm{L}$ vs 980,258 $( \pm 1951.32) \mathrm{ng} / \mathrm{L}$ in patients without SIRS $(\mathrm{P}=0.769)$. In the infected patients, the mean presepsin concentration was $1513.25( \pm 2296.54)$ $\mathrm{ng} / \mathrm{L}$ vs $654.21( \pm 511,068) \mathrm{ng} / \mathrm{L}(\mathrm{P}<0.05)$ calculated among the non infected upon admission. The plasma presepsin concentration increased progressively during the first 8 days of hospitalization. Presepsin concentration in the infected patients was significantly higher than in non-infected patients. On the other hands no significant differences were found in the plasma level of presepsin among patients with and without SIRS. Any other clinical condition related to the trauma did not affect presepsin. Our data clearly suggest that presepsin may be considered an helpful diagnostic tool to early diagnose sepsis in trauma patients.

\section{Introduction}

Trauma is the third leading cause of death in western countries after cardiovascular disease and cancer, and it's indeed the leading cause for the population under the age of 45 years (24). Mortality after traumatic events occurs in $45 \%$ of cases several days or weeks after trauma as a result of complications that arise during hospitalization, like sepsis, respiratory distress syndrome (ARDS) and multiple organ failure (MOF) $(7,8,18,22)$. Sepsis is mainly responsible for death within the late complications of traumatic events. The early identification of sepsis and the subsequent implementation of early evidence-based therapies, including pathogen driven antibiotics, have been documented to improve outcomes and to decrease the sepsis-related mortality $(8,9)$. Unfortunately the clinical picture of trauma patients is often a specific due to the release of hormonal, metabolic and immunological mediators $(4,2,13,15,25)$; as a consequence it is generally difficult to differentiate sepsis from non infection related SIRS (systemic inflammatory response syndrome). Even the microbiological testing does not provide definitive diag- 
nostic information since culture based assays remain negative in up to $50 \%$ of cases (8). As stated in the Surviving Sepsis Campaign (SSC) guidelines, published in 2013, in the presence of septic shock, each hour delay in achieving administration of effective antibiotics is associated with a measurable increase in mortality $(9,14)$. A useful diagnostic help could come from sepsis biomarkers, which could also guide the timing of antibiotic therapy and play a prognostic role $(19,21)$. The identification of a sensitive and specific biomarker able to early recognize incoming septic complications in trauma patients that at the same time is not influenced by concomitant traumatic injuries, is still a challenge for researchers and the aim of this study is fitting this research frame. A long series of potential biomarkers for sepsis, many of which are of no clinical utility due to poor sensitivity and specificity are described in the recent scientific literature $(19,21)$. Several studies demonstrated the clinical utility of one of these new biomarkers: presepsin (sCD14-ST). Presepsin is reported to be valuable for the early diagnosis of sepsis, the patients risk stratification, and the evaluation of prognosis in septic patients $(11,16,23,26)$. This soluble protein of $13 \mathrm{kDa}$ is produced by the plasma protease starting from the soluble form of the membrane glycoprotein CD14 which is expressed on the surface of monocytes, macrophages and granulocytes. CD14 is a high affinity receptor for lipopolysaccharide (LPS) and for the lipopolysaccharide binding protein (LBP). After the binding between LPS and CD14 through the LBP the transduction of a series of signals is activated. This process lead to the release of numerous cytokines that promote the inflammatory cascade. The soluble form of CD14 of which presepsin is a sub-type (sCD14-ST) is also liberated $(6,16,21)$. According to several studies, plasma levels of presepsin increased significantly in infected patients compared to those with SIRS and non-infected ones. $(11,12,14,16,17,23,26)$. Presepsin levels increase in the early stages of sepsis before other clinical signs of infection are present, and they further enhance during its progression, reaching the greatest values in the stage of septic shock (16). This data suggest that presepsin can be a good biomarker to support clinicians in the management of septic patients. In this study 48 poly-trauma patients were enrolled: based on this population the evolution of presepsin plasma concentrations during the first 8 days of hospitalization in intensive care and its relationship with infections has been studied. The principal aim was to establish if the level of presepsin in plasma is or not influenced by traumatic injuries or by the SIRS status: as a consequence the principal goal of the study was to assess the potential usefulness of presepsin evaluation for the early detection of incoming septic complications in patients suffering from trauma.

\section{Materials and Methods}

This retrospective study was performed on 48 patients suffering poly-trauma and admitted from July 2013 to October 2014 to intensive care units in the Romagna area (northern Italy): 46 subjects were hospitalized at the M. Bufalini hospital in Cesena, and 2 at the S.M. delle Croci hospital in Ravenna. All the patients enrolled in the study were $>18$ years. Clinical data for each individual patients were obtained from the consultation of individual medical records. The inclusion criteria were the following: prophylaxis or antibiotic therapy started on admission and maintained for more than 48 hours; on-going infections on admission (not associated with trauma); presence of penetrating injuries; presence of skin lesion with important loss of substance or AISE (abbreviated external injury scale) $>3$; immunosuppressive therapy and/or therapy with steroids; immunosuppression status at the enrolment; death within 8 days for non-infectious reasons. All the patients older than 18 years that meet these criteria in the study period were consecutively enrolled in the study. The following clinical and laboratory data were collected for each individual patient in the study: lactate and base excess (BE) on admission to the emergency room; severity of traumatic injuries according to the ISS score (Injury Severity Score) (BAKER); daily clinical severity [assessed using the SOFA (Sequential Organ Failure Assessment) score, calculated by using the worst daily values]; maximum daily temperature (measured using a bladder thermistor); daily plasma concentration of creatinin. Each patient was also evaluated daily for the presence of SIRS and for the onset of infections. The plasma level of presepsin (presepsinemia) was evaluated at 24 hours after admission, and on the $3^{\text {rd }}, 5^{\text {th }}$ and $8^{\text {th }}$ day of hospitalization. The concentration of presepsin was evaluated in left over samples originally used for the counting of whole blood cells in EDTA containing (ethylene diamine tetra acetic acid) tubes. Samples were collected and stored according to the manufacturer instructions until used for the analysis that was performed using the PATHFAST® system (Mitsubishi Chemical Medience Corporation, Tokyo, Japan). This automated instrument measures the plasma concentration of presespsin by using magnetic particles coated with presepsin specific mouse monoclonal antibodies and polyclonal antibodies obtained from rabbits labelled with alkaline phosphatase (ALP labelled antibody). The presepsin in blood sample (whole blood or plasma) binds to anti-presepsin antibodies and to ALP labelled antibody, to form an immune complex. After removing unbound labelled ALP antibodies using the MAGTRATION ${ }^{\circledR}$ technology (the magnetic particles are washed directly into the tube), a chemiluminescent substrate is added to the immune complex. After a short incubation period (10 minutes), the luminescence generated by the enzymatic reaction is detected by a photometer and, by measuring the emitted light, the concentration of presepsin in the samples calculated. The whole procedure is automatically performed using the PATHFAST analyser in about 15 minutes and requires a total volume of $100 \mu \mathrm{L}$ sample. The SIRS status and the presence of infection have been investigated retrospectively, based on data obtained from individual clinical record and considering the complete set of clinical manifestations, the laboratory tests and imaging data, the results obtained by standard of care microbiological testing (blood cultures, tracheal aspirates, bronco lavages, urine cultures) according to the International Sepsis Forum Consensus Conference on Definitions of Infection criteria (10).

\section{Statistical analysis}

Data were reported as mean and standard deviation (SD) for continuous variables, as median and interquartile range (IQR) for ordinal variables and as percentage for the frequency distributions. The distribution of data was evaluated preliminarily using the Kolmogorov-Smirnov test. A comparison between means was performed using the Student t-test for independent samples, for continuous variables with a normal distribution, and the MannWhitney U test for continuous variables with non-normal distributions and non-continuous ordinal variables. The comparison among the frequency distributions was made using the Chi-square test and the correlation between variables was assessed with the Spearman's rank correlation test.

\section{Results}

The demographic characteristics of the 48 patients enrolled are summarised in in Table 1. Only one patient was found to be infected upon enrolment, with a clinical picture of septic shock resulting 
from intestinal ischemia, due to acute traumatic vascular injury and intestinal micro perforation. This infection was clearly linked to the traumatic event and consequently the patient was included in the study. The infected patient, male, $65 \mathrm{y}-0$, was hospitalized in intensive care for 56 days, and was discharged alive. The following data stated trauma severity in this patient: ISS 24, lactate $2 \mathrm{mmol} / \mathrm{L}$ and $\mathrm{BE} 0.3 \mathrm{mmol} / \mathrm{L}$ on admission to the emergency room. In the first 24 hours, the patient was transfused with 5 units of packed red blood cells ( 1 unit $=280 \mathrm{~mL}$ ) and 2 of fresh frozen plasma ( 1 bag $=500 \mathrm{~mL}$ ). The trauma severity data of the non-infected patients on admission, were as follows; median ISS: 25 (IQR 20,25); average lactate values: $2.9 \pm 2 \mathrm{mmol} / \mathrm{L}$ and average $\mathrm{BE}$ values: $-5.1 \pm 4.6$ $\mathrm{mmol} / \mathrm{L}$. The first 24 hours, non-infected patients were transfused with an average of $2.4 \pm 4.1$ units of packed red blood cells, $0.4 \pm 0.8$ units of platelets ( 1 unit $=250 \mathrm{~mL}$ ) and $0.6 \pm 1.3$ of fresh frozen plasma bags. The trauma-related data are summarized in Table 2.

Table 3 summarises the average values on the first day of admission in the ICU of presepsinaemia, lactate, creatinin and temperature of uninfected patients, and their SOFA severity scores. The 47 uninfected patients' presepsinaemia average value was $504.7 \pm 474.7 \mathrm{ng} / \mathrm{L}$ on the first day of admission. The two highest values of presepsin in uninfected patients (1585 ng/L and $1209 \mathrm{ng} / \mathrm{L})$, have been observed in patients with hepatic injury. Specifically, in a patient with active $\mathrm{HCV}$-related liver disease, and in a patient who was subjected to

Table 1. Demography of the studied population.

\begin{tabular}{lc} 
Characteristic & \\
Mean age (SD) & 47.6 years $( \pm 19.0)$ \\
Gender & $39(79.3 \%)$ \\
Male & $9(20.7 \%)$ \\
\hline
\end{tabular}

SD, standard deviation.

Table 2. Summary of the trauma-related parameters.

\begin{tabular}{lcc} 
Trauma-related data & Missing patients \\
ISS, median (IQR) & $25(20.25)$ & 1 \\
ER lactate, mean (SD) & $2.9(1,8)$ & 7 \\
\hline ER base excess, mean (SD) & $-5.1(4.6)$ & 5 \\
\hline
\end{tabular}

SD, standard deviation.

Table 3. Average values (standard deviation) detected on the first day of admission in the Intensive Care Unit for presepsin plasma concentration, lactate, creatinin. The last two lanes contains data about temperature and SOFA severity scores for the uninfected patients.

\begin{tabular}{lc} 
Parameters & Mean (SD) \\
Presepsin & $504.7(474.7)$ \\
Lactate & $2.1(1.1)$ \\
\hline Creatinin & $0.98(0.52)$ \\
Temperature max, C & $37.9(0.7)$ \\
\hline SOFA, IQR & $8(4)$ \\
\hline
\end{tabular}

hepatic packing. Correlation between presepsinaemia dosed on the first day of hospitalization and the ISS score was analysed using the Spearman Rho test and found to be -0.27 (Figure 1A); we also tested the correlation between presepsinaemia on the first day and lactate (Figure $1 \mathrm{~B})$ and BE dosed in the emergency room (0.211 and -0.251 respectively). We found that there is no correlation between these parameters and the value of presepsinaemia on the first day of hospitalization. Among the 47 non-infected patients on admission, $15(31.25 \%)$ showed a clinical SIRS during the first day in hospital. The mean presepsinaemia at the first day in these uninfected patients with SIRS was $657.6 \pm 739.4 \mathrm{ng} / \mathrm{L}$, whilst the average value of presepsin in $32(68.75 \%)$ uninfected patients without SIRS was $435.2 \pm 275.3 \mathrm{ng} / \mathrm{L}$. There was no significant difference in the presepsinaemia measured in the first day of hospitalization between non-infected patients with and without SIRS $(\mathrm{P}=0.275)$. Below, the evolution of SIRS, of infection and presepsinaemia states in trauma patients during the first 8 days of hospitalization in ICU is detailed.

Figure 2 shows the percentage of patients suffering from SIRS and/or infections at the $1^{\text {st }}, 3^{\text {rd }}, 5^{\text {th }}$ and $8^{\text {th }}$ day of hospitalization. The presepsinemia was measured at the same time intervals: the average values of presepsin in the total 48 patients enrolled are shown in Figure 3. In the only patient infected on admission, presepsinaemia on the $1^{\text {st }}$ day was $2963 \mathrm{ng} / \mathrm{L}$, that is six times higher than the average value of presepsin found in uninfected patients. The average values of presepsin calculated during the time interval of the study for infected and uninfected patients are shown in Figure 4. The highest absolute value of presepsinaemia was observed in an infected patient on the $8^{\text {th }}$ day $(4063 \mathrm{ng} / \mathrm{L})$. This patient had liver lesions, and from the first day he showed higher values of plasma presepsin concentration than other non-infected patients. Among the patients with SIRS, the mean concentration of presepsin was $917.086( \pm 69.042) \mathrm{ng} / \mathrm{L}$ while this value was $980,258( \pm 1951.32) \mathrm{ng} / \mathrm{L}$ in patients without SIRS $(\mathrm{P}=0.769)$ (Figure 5A). The infected patients showed a mean concentration of presepsin of $1513.25( \pm 2296.54) \mathrm{ng} / \mathrm{L}$ being $654.21( \pm 511,068)$ $\mathrm{ng} / \mathrm{L}$ in the non infected patients $(\mathrm{P}<0.05)$ (Figure $5 \mathrm{~B})$.

\section{Discussion}

The early diagnosis and clinical scoring of the severity of sepsis increases the possibility to start a timely and specific therapy in order to reduce mortality and improving the clinical outcomes of the patients in the ICU. Because of the complex and nonspecific clinical picture associated with trauma it is often quite difficult to make an early diagnosis of the septic development and to differentiate sepsis from SIRS. Several studies already demonstrated the utility of presepsin in the process of early identification of septic conditions in different clinical ICU setting other than trauma affected patients $(17,28)$. In this study we want to study the role of presepsin in patients entering the ICU immediately after an acute trauma occurred, so that any other clinical condition that could influence the level of presepsin concentration in plasma is basically excluded.

The variation of presepsinaemia during the first 8 days of hospitalization in the ICU was evaluated and this parameter was correlated to the onset of infections: this correlation allowed us to establish that there is an increasing trend of the values of presepsinaemia and these increased over time values are strictly linked to the increase of the percentage of patients with an infection. The sample population is indeed not large enough to draw an overall robust conclusion, however, the evaluation of the presepsinaemia values trend is likely a clinically valuable support in the management of these trauma affected patients.. 
Our results also demonstrated that there is no significant correlation between the presepsinaemia values after 24 hour from traumatic event and the severity of injuries expressed according to the ISS score $(\mathrm{P}=-0.27)$. These data, suggest that presepsinaemia is not affected by the extent of the traumatic injury in non-infected patients.

The clinical evaluation on admission of the 47 patients who were uninfected allowed to differentiate two groups: 15 patients had SIRS, whilst 33 did not have clinical SIRS evidence. A statistical analysis showed that there was no significant difference between presepsinaemia values in patients with SIRS and in those without SIRS $(\mathrm{P}=0.275)$. Even when all the collected samples were evaluated, no significant difference in the presepsinaemia was observed between the group with SIRS and without SIRS $(\mathrm{P}=0.769)$. These results suggest that presepsin may represent an appropriate marker for the early detection of infections related to trauma, since it is not affected by the SIRS status. The presepsinaemia values in infected patients showed a significant increase when compared to the presepsin concentrations detected among non-infected trauma patients $(\mathrm{P}<0.05)$ according to the evidence already shown in the in literature $(16,28)$.

It was also of interest to analyse the data obtained for the only one enrolled patient who was already infected, with a clinically trauma related infection, upon admission: the value of presepsinaemia in the first day was 6 times greater than the average values detected for the non-infected group (2963 ng/L). A very high absolute value on admission could thus suggest the presence of infection, even if it is of note that presepsin concentrations usually increase with age and kidney dysfunction. As a consequence, the interpretation of presepsin concentrations must also take into account the age of the patients and their liver and kidney function (6). All the patients included in this study did not show any renal problems during the first 24 hours; however two patients had liver lesions on admission and, although not infected, had presepsinaemia values respectively of $1585 \mathrm{ng} / \mathrm{L}$ and $1209 \mathrm{ng} / \mathrm{L}$. The mechanisms for producing and eliminating presepsin are not yet fully known and it is thus possible to consider that in addition to the renal system, the hepatic system could also be involved.
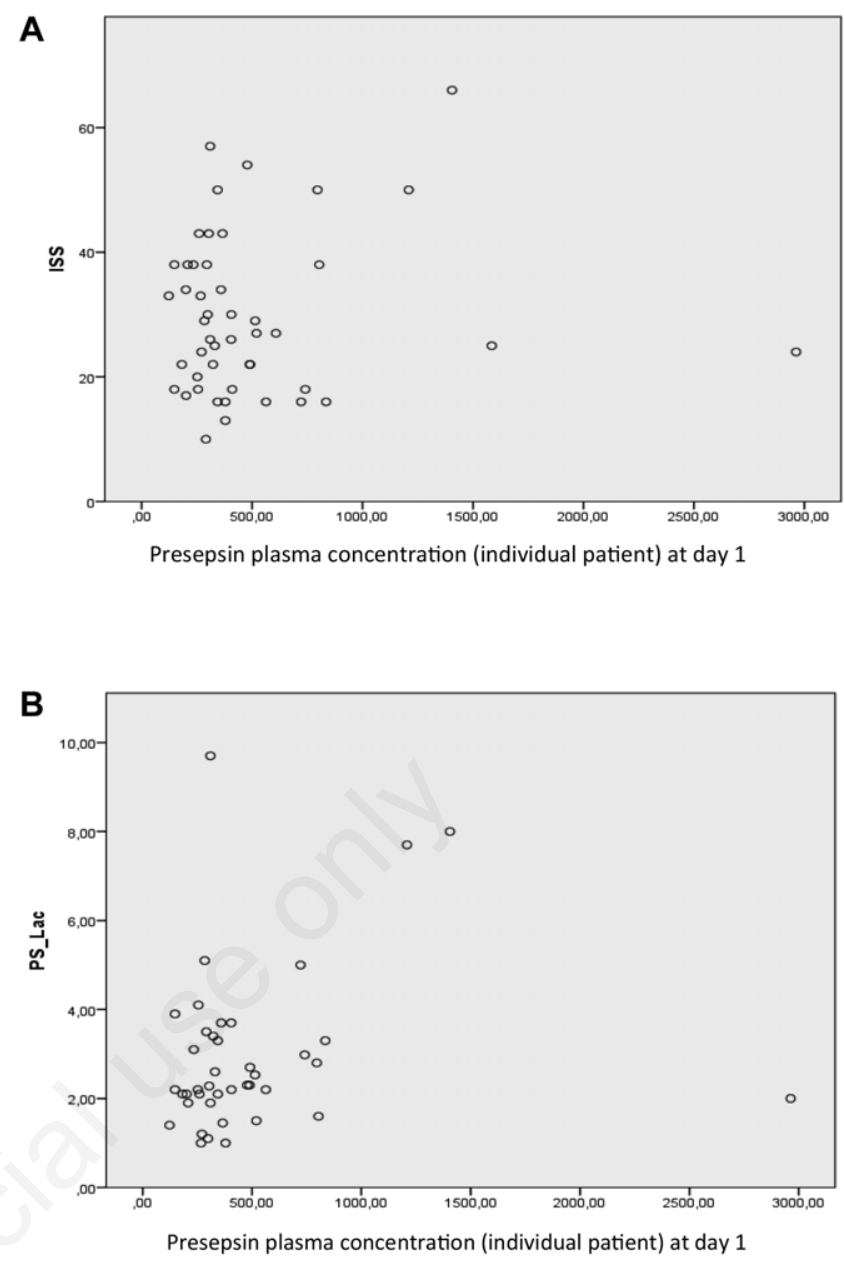

Figure 1. Correlation between presepsinaemia at the first day of hospitalization and A) ISS score, B) lactate.

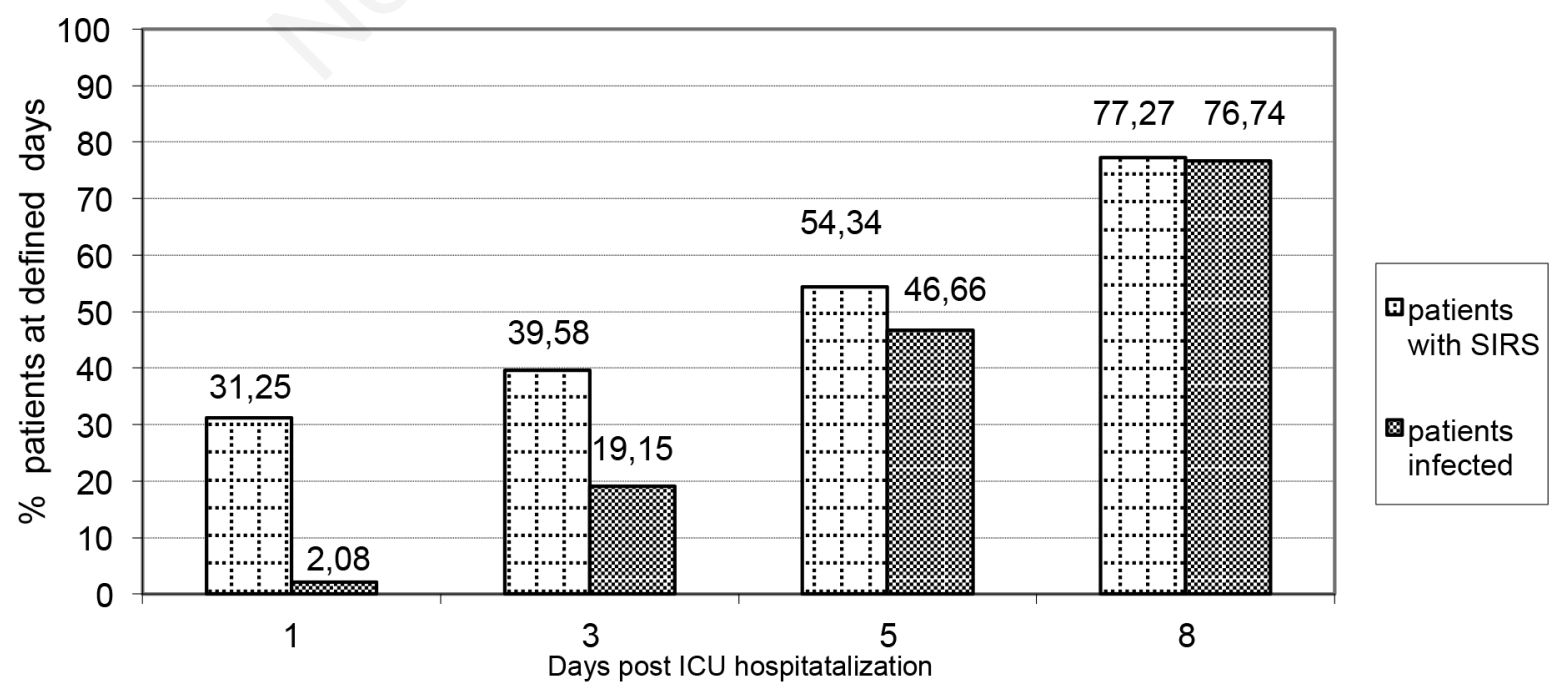

Figure 2. Percentage of patients suffering from SIRS and/or infections at the $1^{\text {st }}, 3^{\text {rd }}, 5^{\text {th }}$ and $8^{\text {th }}$ day of hospitalization. 


\section{Conclusions}

In conclusion, blood presepsin levels significantly increased in trauma patients who are infected, compared to the non-infected ones; nor SIRS status, neither trauma injuries influenced presepsin concentrations. These data allow to conclude that the detection of presepsin plasma concentration over time on a regular schedule from day 1 to 8 could play an important and potentially helpful role in the in early diagnosis of sepsis in trauma patients. One important limitation of this study is indeed the small number of patients enrolled. Additional further studies on larger populations are needed to better and deeper investigate the diagnostic role of presepsin in trauma patients, and also to investigate its prognostic value and its ability to predict therapeutic efficacy.

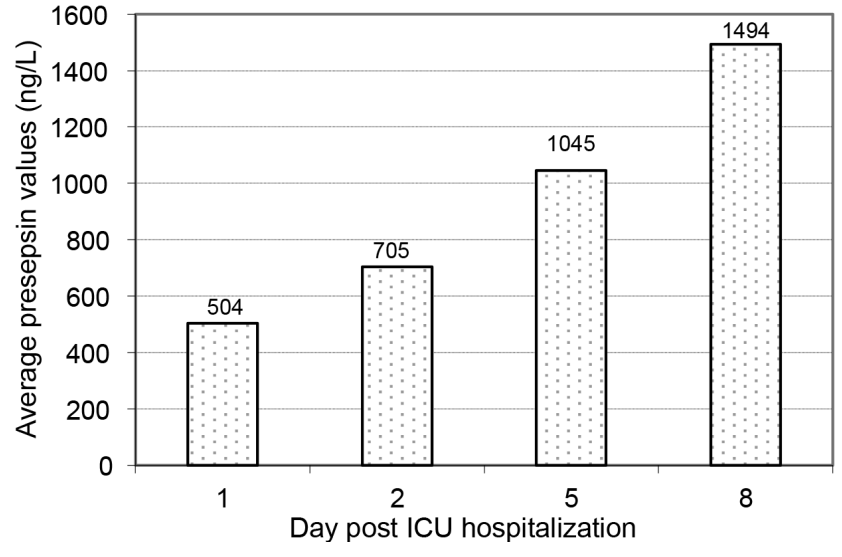

Figure 3. Average values of presepsin plasma concentration in the total 48 patients enrolled over the time $\left(1^{\text {st }}, 3^{\text {rd }}, 5^{\text {th }}\right.$ and $8^{\text {th }}$ day of hospitalization).

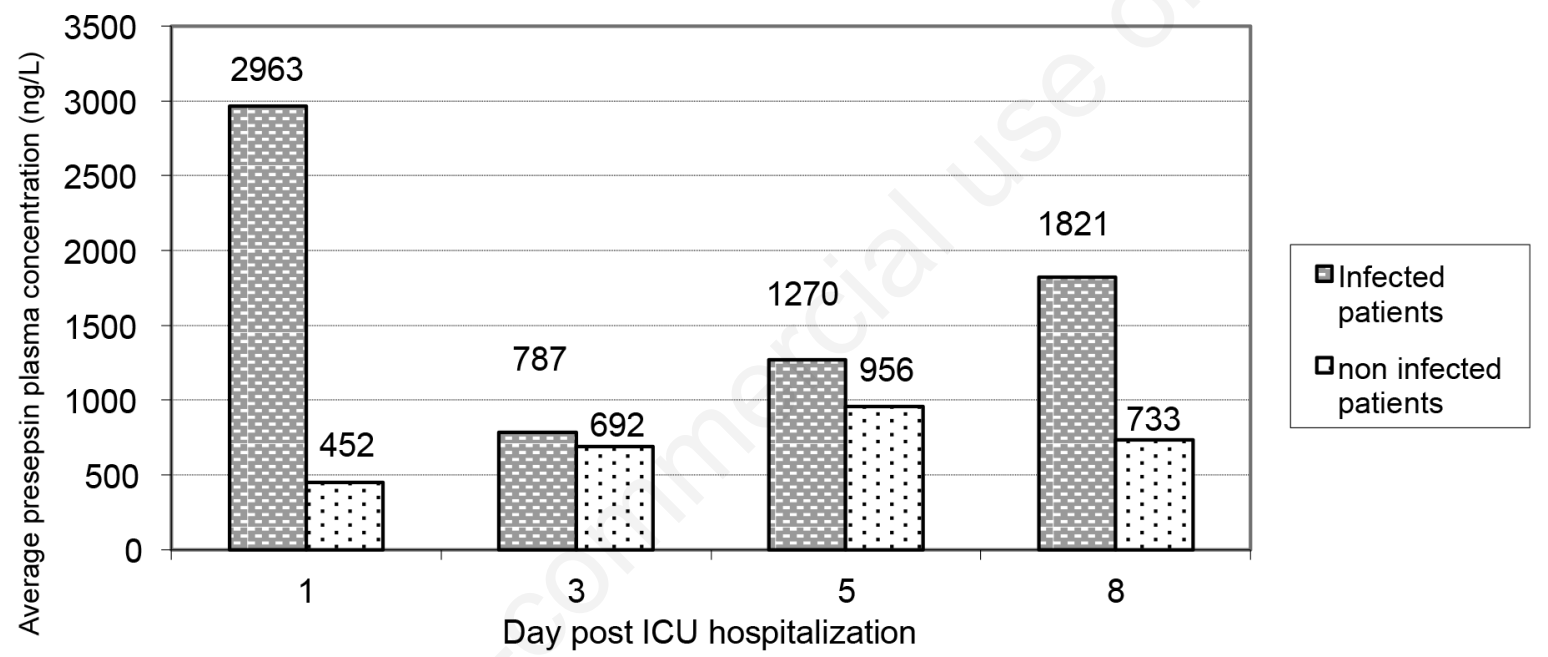

Figure 4. Average values of presepsin plasma concentration calculated during the time interval of the study for infected and non-infected patients.

A

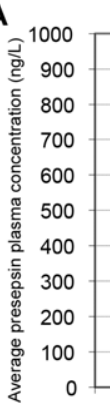

980,02

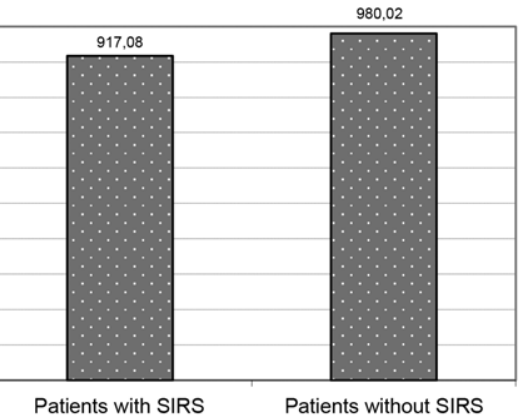

-
B

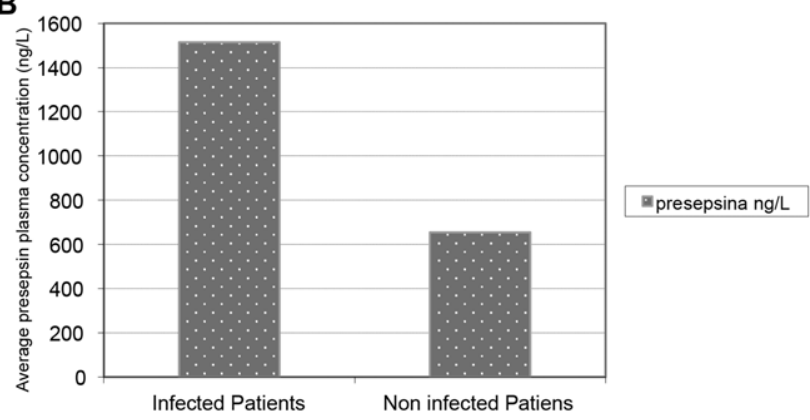

Figure 5. Cumulative average values of presepsin calculated for the total time study for A) patients with and without SIRS; B) infected and non-infected patients. 


\section{References}

1. Atkinson AJ, Colburn WA, DeGruttola VG, et al. Biomarkers and surrogate endpoints: preferred definitions and conceptual framework. Clin Pharmacol Ther 2011;69:89-95.

2. Billeter A, Turina N, Seifert B, et al. Early serum Procalcitonin, Interleukin-6, and 24-hour lactate clearance: useful indicators of septic infections in severely traumatized patients. World J Surg 2009;33:558-6.

3. Bouadma L, Luyt C, Tubach F, et al. Use of procalcitonin to reduce patients' exposure to antibiotics in intensive care units (PRORATA trial): a multicentre randomised controlled trial. Lancet 2010;375:463-74.

4. Brøchner AC, Toft P. Pathophysiology of the systemic inflammatory response after major accidental trauma. Scand J Trauma Resusc Emerg Med 2009; 17:43.

5. Castelli GP, Pognani C, Cita M, et al.. Procalcitonin as a prognostic and diagnostic tool for septic complication after major trauma. Crit Care Med 2009;37:1845-9.

6. Chenevier-Gobeaux C, Trabattoni E, Roelens $\mathrm{M}$, et al. Presepsin (sCD14-ST) in emergency department: the need for adapted threshold values? Clin Chim Acta 2014;427:34-6.

7. Chiara O, Cimbanassi S, Pitidis A, et al. Preventable trauma deaths: from panel review to population based-studies. World J Emerg Surg 2006;1:12.

8. Ciriello V, Gudipati S, Stavrou PZ et al. Biomarkers predicting sepsis in polytrauma patients: current evidence. Injury 2013;44:1680-92.

9. Dellinger RP, Levy MM, Rhodes A, et al. Surviving sepsis campaign guidelines committee including the pediatric subgroup. Surviving sepsis campaign: international guidelines for management of severe sepsis and septic shock: 2012. Crit Care Med 2013;41:580-37.

10. Dupuy AM, Philippart F, Pean Y, et al. Role of biomarkers in the management of antibiotic therapy: an expert panel review: I - currently available biomarkers for clinical use in acute infections. Ann Inten Care 2013;3:22.

11. Endo S, Suzuki Y, Takahashi G, et al. Usefulness of presepsin in the diagnosis of sepsis in a multicenter prospective study. Infect Chemother 2012;18:891-7.

12. Endo S, Suzuki Y, Takahashi G, et al. Presepsin as a powerful monitoring tool for the prognosis and treatment of sepsis: a multicenter prospective study. Infect Chemother 2014;20:30-4.

13. Giannoudis PV. Current concepts of the inflammatory response after major trauma: an update. Injury 2003;34:397-4.
14. Kopterides P, Tsangaris I. Procalcitonin and sepsis: recent data on diagnostic utility, prognostic potential and therapeutic implications in critically ill patients. Minerva Anestesiol 2012;78:823-35.

15. Levy MM. Preface biomarkers in critical illness. Crit Care Clin 2011;27:13-5.

16. Liu B, Chen YX, Yin Q, et al. Diagnostic value and prognostic evaluation of presepsin for sepsis in an emergency department. Crit Care 2013;17:R244.

17. Masson S, Caironi P, Spanuth E, et al. Presepsin (soluble CD14 subtype) and procalcitonin levels for mortality prediction in sepsis: data from the Albumin Italian Outcome Sepsis trial. Crit Care 2014;18:R6.

18. Pfeifer R, Tarkin IS, Rocos B et al. Patterns of mortality and causes of death in polytrauma patients: has anything changed? Injury 2009;40:907-11.

19. Pierrakos C, Vincent JL. Sepsis biomarker: a review. Crit Care 2010;14:R15.

20. Prkno A, Wacker C, Brunkhorst FM, et al. Procalcitonin-guided therapy in intensive care unit patients with severe sepsis and septic shock-a systematic review and meta-analysis. Crit Care 2013;17:R291.

21. Sankar V, Webster NR. Clinical application of sepsis biomarkers. J Anesth 2013;27:269-83.

22. Sauaia A, Moore F, Moore EE, et al. Epidemiology of trauma deaths: a reassessment. J Trauma 1995;38:185-93.

23. Shozushima T, Takahashi G, Matsumoto N, et al. Usefulness of presepsin (sCD14-ST) measurements as a marker for the diagnosis and severity of sepsis that satisfied diagnostic criteria of systemic inflammatory response syndrome. J Infect Chemother 2011;17:764-9.

24. Trunkey DD, Blaisdell FW. Epidemiology of trauma. Sci Am 1988;4:1-7.

25. Tsukamoto T, Chanthaphavong SR, Pape HC. Current theories on the pathophysiology of multiple organ failure after trauma. Injury 2010;41:21-6.

26. Ulla M, Pizzolato E, Lucchiari M, et al. Diagnostic and prognostic value of presepsin in the management of sepsis in the emergency department: a multicenter prospective study. Crit Care 2013;17:R168.

27. Vincent JL, Moreno R, Takala J, et al. The SOFA (Sepsis-related Organ Failure Assessment) score to describe organdysfunction/failure. Inten Care Med 1996;22:707-10.

28. Yaegashi Y, Shirakawa K, Sato N, et al. Evaluation of a newly identified soluble CD14 subtype as a marker for sepsis. J Infect Chemother 2005;11:234-8. 